\title{
Improving Nitrogen Status Estimation in Malting Barley Based on Hyperspectral Reflectance and Artificial Neural Networks
}

\author{
Karel Klem ${ }^{1,2, *} \mathbb{D}$, Jan Křen ${ }^{2}{ }^{\mathbb{D}}$, Ján Šimor ${ }^{2}$, Daniel Kováč ${ }^{1}$, , Petr Holub ${ }^{1}$, Petr Míša ${ }^{3}$, Ilona Svobodová ${ }^{3}$, \\ Vojtěch Lukas ${ }^{2}{ }^{(}$, Petr Lukeš ${ }^{1}$, Hana Findurová ${ }^{1,2}$ and Otmar Urban ${ }^{1}(\mathbb{C}$ \\ 1 Global Change Research Institute CAS, Bělidla 986/4a, 60300 Brno, Czech Republic; \\ kovac.d@czechglobe.cz (D.K.); holub.p@czechglobe.cz (P.H.); lukes.p@czechglobe.cz (P.L.); \\ findurova.h@czechglobe.cz (H.F.); urban.o@czechglobe.cz (O.U.) \\ 2 Faculty of AgriSciences, Mendel University in Brno, Zemědělská 1/1665, 61300 Brno, Czech Republic; \\ jan.kren@mendelu.cz (J.K.); jan.simor@gmail.com (J.Š.); vojtech.lukas@mendelu.cz (V.L.) \\ 3 Agrotest Fyto, Ltd., Havlíčkova 2787/121, 76701 Kromeriz, Czech Republic; misa@vukrom.cz (P.M.); \\ svobodova@vukrom.cz (I.S.) \\ * Correspondence: klem.k@czechglobe.cz; Tel.: +420-724-285-737
}

Citation: Klem, K.; Křen, J.; Šimor, J.; Kováč, D.; Holub, P.; Míša, P.; Svobodová, I.; Lukas, V.; Lukeš, P.; Findurová, H.; et al. Improving Nitrogen Status Estimation in Malting Barley Based on Hyperspectral Reflectance and Artificial Neural Networks. Agronomy 2021, 11, 2592. https://doi.org/10.3390/ agronomy 11122592

Academic Editors: Christos Noulas, Shahram Torabian and Ruijun Qin

Received: 12 November 2021 Accepted: 17 December 2021 Published: 20 December 2021

Publisher's Note: MDPI stays neutral with regard to jurisdictional claims in published maps and institutional affiliations.

Copyright: (c) 2021 by the authors. Licensee MDPI, Basel, Switzerland. This article is an open access article distributed under the terms and conditions of the Creative Commons Attribution (CC BY) license (https:// creativecommons.org/licenses/by/ $4.0 /)$.

\begin{abstract}
Malting barley requires sensitive methods for $\mathrm{N}$ status estimation during the vegetation period, as inadequate $\mathrm{N}$ nutrition can significantly limit yield formation, while overfertilization often leads to an increase in grain protein content above the limit for malting barley and also to excessive lodging. We hypothesized that the use of $\mathrm{N}$ nutrition index and $\mathrm{N}$ uptake combined with red-edge or green reflectance would provide extended linearity and higher accuracy in estimating $\mathrm{N}$ status across different years, genotypes, and densities, and the accuracy of $\mathrm{N}$ status estimation will be further improved by using artificial neural network based on multiple spectral reflectance wavelengths. Multifactorial field experiments on interactive effects of N nutrition, sowing density, and genotype were conducted in 2011-2013 to develop methods for estimation of N status and to reduce dependency on changing environmental conditions, genotype, or barley management. $\mathrm{N}$ nutrition index (NNI) and total $\mathrm{N}$ uptake were used to correct the effect of biomass accumulation and $\mathrm{N}$ dilution during plant development. We employed an artificial neural network to integrate data from multiple reflectance wavelengths and thereby eliminate the effects of such interfering factors as genotype, sowing density, and year. NNI and N uptake significantly reduced the interannual variation in relationships to vegetation indices documented for $\mathrm{N}$ content. The vegetation indices showing the best performance across years were mainly based on red-edge and carotenoid absorption bands. The use of an artificial neural network also significantly improved the estimation of all $\mathrm{N}$ status indicators, including $\mathrm{N}$ content. The critical reflectance wavelengths for neural network training were in spectral bands 400-490, 530-570, and 710-720 nm. In summary, combining NNI or $\mathrm{N}$ uptake and neural network increased the accuracy of $\mathrm{N}$ status estimation to up $94 \%$, compared to less than $60 \%$ for $\mathrm{N}$ concentration.
\end{abstract}

Keywords: artificial neural network; grain yield; Hordeum vulgare; nitrogen status; hyperspectral reflectance

\section{Introduction}

Malting barley ranks among the most challenging crops, concerning its nitrogen (N) nutrition. This is mainly due to the very narrow $\mathrm{N}$ optima of barley, which is constrained by grain yield on the one hand, and by grain protein content on the other, extensively affecting malting quality [1,2]. Insufficient $\mathrm{N}$ nutrition, particularly at the beginning of vegetation, leads to weak tillering, reduced grain size, and low grain yield [3]. Conversely, excessive $\mathrm{N}$ nutrition and, in particular, greater $\mathrm{N}$ availability at later growth stages leads to an immediate increase of protein content in grain, also negatively influencing other malting quality parameters [4]. The grain protein content is closely related to canopy $\mathrm{N}$ due to its 
extensive translocation to grain and the transformation into grain protein during grain filling. However, these processes are also significantly modulated by water availability and temperatures, limiting the starch synthesis and accumulation in grain, resulting in an altered relative proportion of protein and starch in grain [3,5].

Moreover, $\mathrm{N}$ overfertilization has adverse effects through increasing crop density and subsequent lodging, which can lead to reduced yields and other indirect negative impacts on grain quality, such as contamination by mycotoxins [6,7]. The difference between suboptimal and excessive $\mathrm{N}$ nutrition status may, in malting barley, be less than $30 \mathrm{~kg} \mathrm{~N} \mathrm{ha}^{-1}$, and its demands change considerably through different stages of the crop's development. Precise optimization of $\mathrm{N}$ nutrition is thus essential to ensure high production and top quality of malting barley in parallel.

Methods presently used for optimizing $\mathrm{N}$ status based on soil and plant analyses are relatively expensive, labor-intensive, and scarcely allow for evaluating spatial and temporal variability in $\mathrm{N}$ availability on large scales [8]. Therefore, the application of remote sensing, and in particular of reflectance spectroscopy, has recently received considerable attention for estimating $\mathrm{N}$ status $[9,10]$. Diagnostics of $\mathrm{N}$ status in plants using spectral reflectance is usually based on a very close correlation between the concentrations of $\mathrm{N}$ and chlorophyll, and thus on the absorption properties of chlorophyll $\mathrm{a}+\mathrm{b}$ [11]. Although specific absorption coefficients of chlorophylls are high for the critical absorption bands (red and blue), the depth of light penetration into the leaf is low, and the changes of reflectance in these bands with changing chlorophyll content are saturated already at medium chlorophyll concentrations per area unit [12]. As a result, widely applied indices based on red and blue reflectance have been found to be insufficiently sensitive to changes at medium and high chlorophyll or $\mathrm{N}$ content [13]. One of the essential prospects for improving the estimation of $\mathrm{N}$ status thus lies in using green and, particularly, red-edge reflectance regions [14], which provide greater sensitivity to chlorophyll and $\mathrm{N}$ at higher contents with simultaneous increase of linearity [15]. Despite these improvements in N status estimation, many authors still indicate considerable effects of genotype, year, growth stage, and crop density on estimation accuracy [16-19].

Besides the use of sensitive vegetation indices, the way to improve the estimation of $\mathrm{N}$ status under such variable conditions leads through estimating indicators of $\mathrm{N}$ status, which are less dependent on growth stage, biomass, variety, or density. The relative $\mathrm{N}$ nutrition index (NNI) was introduced in order to allow expression of $\mathrm{N}$ status under the rapid dilution of $\mathrm{N}$ content during growth [20]. NNI provides the opportunity to express the relative $\mathrm{N}$ status independently of the growth stage based upon the so-called critical or dilution $\mathrm{N}$ curve, which reflects the minimum $\mathrm{N}$ concentration required to achieve maximum growth or yield [21]. NNI or integrated $\mathrm{N}$ uptake per area unit (N uptake) also seem to be more easily estimated by remote sensing methods and are more stable in time than the estimation of $\mathrm{N}$ content in plant biomass [10].

Neither the use of more sensitive reflectance indices based on green and red-edge wavebands nor NNI or N uptake can provide complete decoupling of the relationship between spectral reflectance and $\mathrm{N}$ status from the effects of such other factors as canopy structure, genotype, or other environmental conditions. However, it is possible to eliminate uncertainties given by the impact of different factors on spectral reflectance signature by using sophisticated multifactorial methods such as PLS regression or artificial neural networks if trained on sufficiently complex data [22].

We hypothesized that the combination of vegetation indices based on red-edge and green reflectance with NNI and N uptake as indicators of N status in malting barley would provide extended linearity and higher accuracy in estimating $\mathrm{N}$ status across different years, genotypes, and densities, as compared to indices based on red or blue reflectance, and also compared to $\mathrm{N}$ content in dry matter. We also assumed that an artificial neural network based on multiple reflectance wavelengths would reduce the uncertainties of $\mathrm{N}$ status estimation caused mainly by interannual variation, genotype, and canopy structure. The main objective of this study was to improve prediction of N status in malting barley using 
spectral reflectance, and particularly to increase the versatility of its use across variable years, genotypes, and management practices, by using three approaches: (i) selecting vegetation indices providing improved linearity of response to $\mathrm{N}$ status and, at the same time, low interannual variability of response; (ii) using the $\mathrm{N}$ status indicators which are less sensitive to changing biomass, growth stage, and rapid dilution of $\mathrm{N}$; (iii) employing the artificial neural networks trained on a wide range of factors that may affect the direct estimation of $\mathrm{N}$ status in malting barley by vegetation indices.

\section{Materials and Methods}

Evaluation of the $\mathrm{N}$ status, canopy reflectance, and yield of spring barley was performed in small-plot field experiments established at the edge of the city of Kroměřiž in Central Moravia (Czech Republic) with coordinates $49^{\circ} 17^{\prime} 5^{\prime \prime} \mathrm{N}, 17^{\circ} 21^{\prime} 35^{\prime \prime}$ E within the period of three consecutive years (2011-2013). The location is characterized by a warm, slightly humid climate with a mean annual temperature of $9.1{ }^{\circ} \mathrm{C}$ and precipitation of $567.7 \mathrm{~mm}$. Weather data during the vegetation period in individual years were collected by a permanent meteorological station located within $500 \mathrm{~m}$ of the experimental field (Table 1). The soil type at the site is Luvi-Haplic Chernozem, and the texture is clay loam. The previous crop was maize for grain in all three years. Standard plant protection measures were used during the growing season to avoid negative interactions with weeds, diseases, and pests. Each experimental treatment represented a combination of three factors, ensuring contrasting differences in the canopy density, structure, and nutritional status: (i) malting barley varieties with different tillering intensity (Bojos-middle, Prestige-low, and Sebastian-high); (ii) sowing density $\left(2.5,4\right.$, and 5.5 million germinating seeds ha $\left.{ }^{-1}\right)$; (iii) $\mathrm{N}$ nutrition $\left(0,45\right.$, and $\left.90 \mathrm{~kg} \mathrm{~N} \mathrm{ha}^{-1}\right)$. $\mathrm{N}$ was applied before sowing in the form of ammonium nitrate. Each treatment was established in five replications. The plot size was $10 \mathrm{~m}^{2}$, and the five replications were arranged in randomized block design. Three replications were harvested for grain yield, and two were used for sampling during vegetation, which enabled the analyses of aboveground biomass and $\mathrm{N}$ content. In sampling plots, squares of size $0.25 \mathrm{~m}^{2}(0.5 \times 0.5 \mathrm{~m})$ were marked out to obtain plants for analyses of canopy structure in two developmental stages: end of tillering to the beginning of stem elongation (DC 29-31) and end of stem elongation (DC 39). Measurements of canopy reflectance in the range 350-2500 nm were made using a FieldSpec 4 HiRes spectroradiometer (ASD, Boulder, CO, USA) and fiber optic cable fixed in pistol grip $\left(25^{\circ}\right.$ field of view $)$. The reflectance measurements were conducted from a distance of ca. $0.8 \mathrm{~m}$ perpendicular to the canopy surface, which ensured the collection of spectra from a circle with a diameter of about $0.36 \mathrm{~m}$. Smooth movement during spectra collection in the distance ca. $2 \mathrm{~m}$ along the plot allowed measurement of reflectance for an area of ca. $0.2 \mathrm{~m}^{2}$. Two reflectance spectra were taken from each plot/replication. Before each new plot, the reference spectrum was measured using the reflectance standard (Spectralon; Labsphere, North Sutton, NH, USA). The reflected radiances were directly converted to spectral reflectance within the RS ${ }^{3}$ Spectral Acquisition Software (ASD). PCA analysis and preliminary correlation with $\mathrm{N}$ nutrition indicators showed that outside the reflectance range $380-850 \mathrm{~nm}$ was the contribution to the explanation of $\mathrm{N}$ status as marginal; therefore, only the average reflectance spectrum in this range from all replications of each treatment was used to calculate vegetation indices (Supplementary Table S1), perform correlation analysis for simple reflectance ratios and normalized difference indices, and to train neural networks.

Analyses of canopy structure and biomass production were performed manually, which involved assessing the numbers of plants and tillers (data not shown) and the quantity of aboveground dry biomass. The aboveground biomass was dried in an oven at $80{ }^{\circ} \mathrm{C}$ until constant weight. The dried plant samples were then analyzed for $\mathrm{N}$ content using a LECO elemental analyzer (LECO, St. Joseph, MI, USA). The harvest was carried out using a Sampo 2010 small-plot harvester equipped with an automatic weighing and sampling system (Sampo Rosenlew, Pori, Finland). The correlation analysis (coefficients of determination, $R^{2}$ ) and neural network training were performed using Statistica 12 
software (StatSoft Inc., Tulsa, USA). Prior to neural network training, the number of input reflectance wavelengths was reduced on the basis of PCA analysis, when reflectance wavelength with the highest PCA scores and lowest (or close to $180^{\circ}$ ) angle in relation to $\mathrm{N}$ status indicators were selected. For the neural network training, each dataset was randomly divided into training (70\%), test (15\%), and validation (15\%) sub-datasets. The training was conducted on 10,000 networks with the maximum number of hidden units as 20 and identity, logistic, exponential, and hyperbolic tangents used for both hidden and output neurons. This allowed achieving high diversity of neural networks from which a set of 10 networks was chosen for each training set on the basis of the lowest training and validation error and the highest $R^{2}$ for the relationship between predicted and observed values. These networks were subjected to another 50 training cycles with new random dividing on training, test, and validation datasets for each. The network showing the lowest variation between training cycles was then selected as the best network. If the variation of performance during 50 training cycles was higher than $25 \%$, the process was repeated. The correlation matrix for normalized difference indices combining all wavelengths of the selected range was analyzed in the software R 3.1.1 (R Foundation for Statistical Computing, Vienna, Austria).

Table 1. Mean daily temperatures and monthly precipitation sums for vegetation period in 2011-2013 and comparison to long-term average values for the period 1971-2010.

\begin{tabular}{ccccccc}
\hline Characteristic & Year & March & April & May & June & July \\
\hline \multirow{3}{*}{$\begin{array}{c}\text { Mean temperature } \\
\left({ }^{\circ} \mathrm{C}\right)\end{array}$} & 2011 & 5.3 & 11.8 & 14.6 & 18.4 & 18.0 \\
& 2012 & 6.6 & 10.6 & 16.3 & 19.1 & 20.8 \\
& 2013 & 1.2 & 10.1 & 14.2 & 17.5 & 21.2 \\
& Long-term average & 4.3 & 9.4 & 14.5 & 17.3 & 19.2 \\
Precipitation sum & $(1971-2010)$ & 35.9 & 45.5 & 84.2 & 72.0 & 119.7 \\
$(\mathrm{~mm})$ & 2011 & 3.1 & 29.2 & 23.8 & 137.2 & 35.3 \\
& 2012 & 51.0 & 33.3 & 87.2 & 129.1 & 2.7 \\
& Long-term average & 32.8 & 40.7 & 66.1 & 80.6 & 73.6 \\
\hline
\end{tabular}

\section{Results}

\subsection{Correlations between Spectral Reflectance and Indicators of $N$ Status}

Evaluation of the index of determination $\left(R^{2}\right)$ was made for the normalized difference indices $N I_{x y}=\left(R_{x}-R_{y}\right) /\left(R_{x}+R_{y}\right)$ at $1 \mathrm{~nm}$ step, wherein $R_{x}$ and $R_{y}$ represent reflectance in wavelengths $x$ and $y$. These normalized indices were correlated to the relative $\mathrm{N}$ content in dry aboveground biomass (\% mass), N nutrition index (NNI; dimensionless), and N uptake by aboveground biomass per area unit ( $\mathrm{N}$ uptake; $\mathrm{kg} \mathrm{ha}^{-1}$ ) separately in the growth stages DC 29-31 and DC 39. Correlations were made across all experimental years, barley genotypes, sowing densities, and $\mathrm{N}$ doses. The results of the correlation analysis are shown in Figure 1, in which the $R^{2}$ are expressed using a color scale for each combination of wavelengths. These results generally show low values of $R^{2}$ for $\mathrm{N}$ content in the aboveground biomass, while for NNI, and particularly for $\mathrm{N}$ uptake, $R^{2}$ increased significantly. This analysis identified several combinations of reflectance wavelengths with the potential for evaluating $\mathrm{N}$ status. Higher $R^{2}$ values were achieved for the combination of reflectance wavelengths in the range of 400-500 nm with 650-690 nm. Another area with relatively high $R^{2}$ values is delineated on both axes by wavelengths in the range 450-490 nm. This narrowly defined area has a particularly closer correlation to the $\mathrm{N}$ status in the growth stage DC 29-31. Similarly, a very narrowly delineated area exhibiting high $R^{2}$ in relation to $\mathrm{N}$ status is defined by reflectance wavelengths in the range 530 $550 \mathrm{~nm}$ on both axes. In this case, however, the higher $R^{2}$ values were obtained only at the later growth stage (DC 39). Similar results were obtained in the area delineated by reflectance wavelengths 560-590 nm. Reliable estimation of N status was also provided 
by $\mathrm{NDI}_{x y}$ when combining reflectance in the range 710-730 $\mathrm{nm}$ with band 730-800 $\mathrm{nm}$. The combination of these bands achieves similar results in both the DC 29-31 and DC 39 growth stages. Comparable results were also performed by a combination of bands 550-650 nm and 730-800 nm. Generally, although these areas overlap for the N content in plants, NNI, and $\mathrm{N}$ uptake, the highest values of $R^{2}$ were obtained for $\mathrm{N}$ uptake and the lowest $R^{2}$ for $\mathrm{N}$ content.

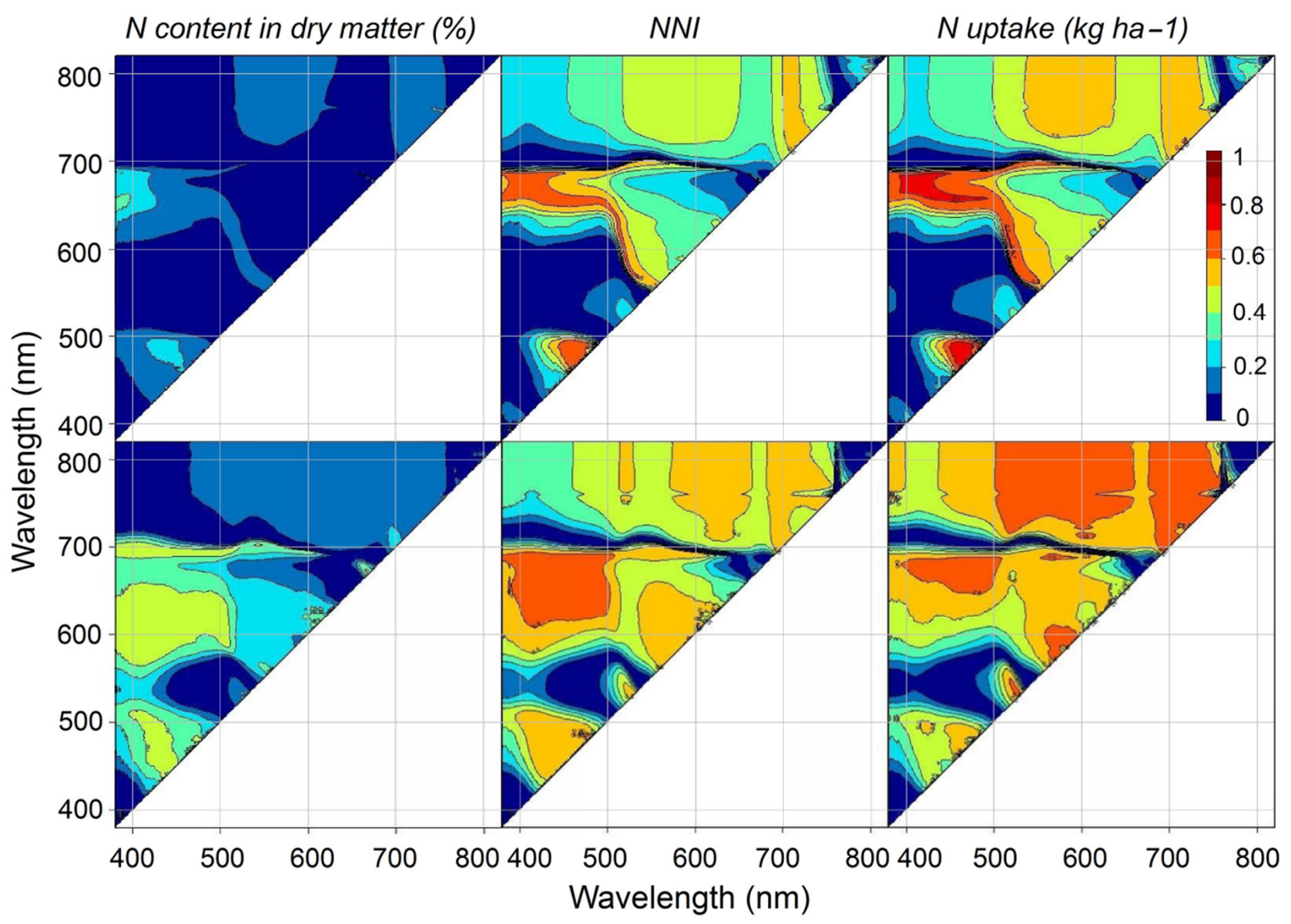

Figure 1. Matrix plots of coefficients of determination $\left(R^{2}\right)$ for the relation of all combinations of wavelengths in the range 380-820 nm used for a linear regression analysis of the normalized difference index $N D I_{x y}=\left(R_{x}-R_{y}\right) /\left(R_{x}+R_{y}\right)$, wherein $R_{x}$ and $R_{y}$ represent reflectance in wavelengths $x$ and $y$, against $N$ content in dry matter (left), nitrogen nutrition index (NNI, middle), and N uptake by aboveground biomass (right). The correlations were calculated separately at stage DC 29-31 (upper) and DC 39 (bottom).

\subsection{Evaluation of N Status Using Vegetation Indices}

From the results of correlation analysis across all experimental years (Table 2), it is evident that in both sampling dates, generally higher $R^{2}$ values were achieved for estimating $\mathrm{NNI}$ and $\mathrm{N}$ uptake than for the $\mathrm{N}$ content in plants. At the same time, the closest correlation to $\mathrm{N}$ status was demonstrated for indices based on a combination of reflectances in bands 430 and $680 \mathrm{~nm}$ (SRPI, NPCI) and also for indices based on reflectance in the red-edge region (700-730 nm), e.g., NRERI, ZM, or $\mathrm{ANMB}_{650-725}$. For such widely used vegetation indices as NDVI, RDVI, and OSAVI, which exploit the differences in reflectance between red and near-infrared bands, the increase of $R^{2}$ with later growth stage was evident. Even in the growth stage DC 39, however, these indices do not outperform the indices based on reflectance in regions around $430 \mathrm{~nm}$ or red-edge band in estimating $\mathrm{N}$ status. As the performances of indices within the abovementioned groups were very similar, we used for further analyses the representatives showing the highest average performance across both 
growth stages and all $\mathrm{N}$ status indicators: SRPI for the region around $430 \mathrm{~nm}$ and NRERI for the red-edge region. The vegetation index NDVI was selected as representative of the group of indices based on reflectance in the red region due to its common use. However, its performance was slightly lower compared to some others within this group.

Table 2. Coefficients of determination $\left(R^{2}\right)$ and root mean square errors (RMSE) for linear relationships between reflectance indices and nitrogen status parameters ( $\mathrm{N}$ content in dry matter, NNI and N uptake by aboveground biomass) at individual growth stages (DC 29-31 and DC 39). Coefficients of determination significant at $p<0.05$ are indicated in bold.

\begin{tabular}{|c|c|c|c|c|c|c|c|c|c|c|c|c|}
\hline \multirow{3}{*}{$\begin{array}{l}\text { Reflectance } \\
\text { Indices }\end{array}$} & \multicolumn{4}{|c|}{ N Content in Dry Matter (\%) } & \multicolumn{4}{|c|}{ NNI } & \multicolumn{4}{|c|}{ N Uptake (kg ha $\left.{ }^{-1}\right)$} \\
\hline & \multicolumn{2}{|c|}{ DC 29-31 } & \multicolumn{2}{|c|}{ DC 39} & \multicolumn{2}{|c|}{ DC 29-31 } & \multicolumn{2}{|c|}{ DC 39} & \multicolumn{2}{|c|}{ DC 29-31 } & \multicolumn{2}{|c|}{ DC 39} \\
\hline & $R^{2}$ & RMSE & $R^{2}$ & RMSE & $R^{2}$ & RMSE & $R^{2}$ & RMSE & $R^{2}$ & RMSE & $R^{2}$ & RMSE \\
\hline $\mathrm{ANMB}_{650-750}$ & 0.19 & 0.437 & 0.21 & 0.378 & 0.61 & 0.137 & 0.52 & 0.126 & 0.68 & 17.00 & 0.60 & 19.68 \\
\hline NDVI & 0.08 & 0.464 & 0.18 & 0.385 & 0.40 & 0.169 & 0.50 & 0.128 & 0.47 & 22.00 & 0.60 & 19.55 \\
\hline NDGI & 0.13 & 0.452 & 0.16 & 0.390 & 0.47 & 0.159 & 0.51 & 0.128 & 0.54 & 20.54 & 0.64 & 18.70 \\
\hline NRERI & 0.23 & 0.424 & 0.17 & 0.386 & 0.62 & 0.135 & 0.53 & 0.125 & 0.68 & 17.02 & 0.66 & 17.98 \\
\hline RDVI & 0.09 & 0.461 & 0.23 & 0.372 & 0.42 & 0.167 & 0.58 & 0.119 & 0.50 & 21.38 & 0.65 & 18.43 \\
\hline MSR & 0.11 & 0.457 & 0.13 & 0.397 & 0.37 & 0.174 & 0.47 & 0.133 & 0.44 & 22.63 & 0.62 & 19.20 \\
\hline MT VI1 & 0.08 & 0.463 & 0.25 & 0.368 & 0.39 & 0.171 & 0.56 & 0.121 & 0.47 & 21.97 & 0.60 & 19.52 \\
\hline TCARI & 0.01 & 0.482 & 0.11 & 0.401 & 0.03 & 0.215 & 0.08 & 0.175 & 0.07 & 29.17 & 0.03 & 30.50 \\
\hline OSAVI & 0.09 & 0.461 & 0.21 & 0.377 & 0.42 & 0.166 & 0.56 & 0.121 & 0.50 & 21.32 & 0.65 & 18.35 \\
\hline TCARI/OSAVI & 0.32 & 0.399 & 0.01 & 0.422 & 0.44 & 0.164 & 0.15 & 0.169 & 0.41 & 23.18 & 0.26 & 26.70 \\
\hline G & 0.07 & 0.468 & 0.18 & 0.385 & 0.29 & 0.184 & 0.48 & 0.139 & 0.36 & 24.08 & 0.56 & 20.68 \\
\hline TVI & 0.08 & 0.465 & 0.25 & 0.367 & 0.38 & 0.172 & 0.56 & 0.121 & 0.47 & 22.07 & 0.60 & 19.75 \\
\hline $\mathrm{ZM}$ & 0.17 & 0.440 & 0.13 & 0.397 & 0.50 & 0.155 & 0.47 & 0.133 & 0.57 & 19.85 & 0.63 & 18.98 \\
\hline SRPI & 0.20 & 0.433 & 0.36 & 0.339 & 0.65 & 0.129 & 0.67 & 0.105 & 0.73 & 15.60 & 0.66 & 18.20 \\
\hline NPQI & 0.11 & 0.457 & 0.26 & 0.365 & 0.04 & 0.215 & 0.36 & 0.146 & 0.01 & 29.98 & 0.31 & 25.74 \\
\hline PRI & 0.18 & 0.439 & 0.25 & 0.368 & 0.61 & 0.136 & 0.29 & 0.154 & 0.66 & 17.61 & 0.23 & 27.23 \\
\hline NPCI & 0.19 & 0.437 & 0.34 & 0.344 & 0.65 & 0.129 & 0.64 & 0.109 & 0.73 & 15.65 & 0.63 & 18.82 \\
\hline SIPI & 0.09 & 0.461 & 0.15 & 0.391 & 0.40 & 0.169 & 0.48 & 0.131 & 0.47 & 22.06 & 0.60 & 19.68 \\
\hline VOG3 & 0.18 & 0.439 & 0.12 & 0.399 & 0.47 & 0.159 & 0.46 & 0.134 & 0.54 & 20.57 & 0.63 & 18.87 \\
\hline VOG2 & 0.18 & 0.439 & 0.12 & 0.398 & 0.48 & 0.158 & 0.47 & 0.133 & 0.54 & 20.36 & 0.64 & 18.67 \\
\hline GM1 & 0.15 & 0.447 & 0.08 & 0.408 & 0.42 & 0.167 & 0.40 & 0.141 & 0.48 & 21.81 & 0.59 & 19.93 \\
\hline GM2 & 0.16 & 0.443 & 0.14 & 0.394 & 0.47 & 0.159 & 0.48 & 0.131 & 0.54 & 20.40 & 0.63 & 18.85 \\
\hline
\end{tabular}

Because the effect of year was the main source of variability in the relationships between vegetation indices and indicators of $\mathrm{N}$ status, detailed regression analysis for selected vegetation indices was carried out separately for individual years. The results are summarized in Table 3 and Figures 2-4. It is evident from these analyses that splitting the relationships by individual year led, in major cases, to higher $R^{2}$ values and lower root mean square errors (RMSE), and this was particularly true for indices NDVI and NRERI and for $\mathrm{N}$ status indicators $\mathrm{NNI}$ and $\mathrm{N}$ uptake. If the relationships are analyzed separately in each year, the $R^{2}$ values are very similar for all three indices (NDVI, NRERI, and SRPI), but especially for estimation of NNI and N uptake. This means that, in particular, the index NDVI, and partly also NRERI, shows a significant effect of the experimental year on relationships between vegetation index and N status indicators. In the case of NDVI, the between-year variation is evident in both the intercept and slope of linear relationships. In NDVI, moreover, an evident change of the index value range was observed for the later growth stage. The NDVI values increased with the later growth stage while the range simultaneously narrowed. This resulted in a rising slope with the later growth stage. In the case of NRERI, a shift of intercept was particularly evident. The slope of linear relationships varied far less, even when comparing the two growth stages. The smallest between-year variation in relationships to N status was found for the index SRPI. Generally, the highest between-year variation in relationships is evident for the $\mathrm{N}$ content in aboveground dry matter. Similarly, the largest differences in relationships between growth stages were observed for this indicator of $\mathrm{N}$ status. The smallest differences in the relationships among growth stages were recorded for $\mathrm{N}$ uptake. 


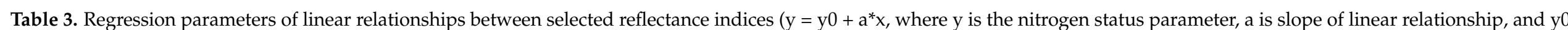

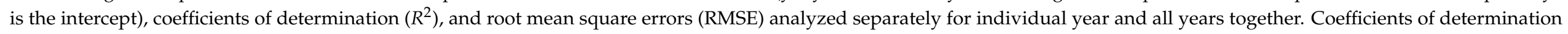
significant at $p<0.05$ are indicated in bold.

\begin{tabular}{|c|c|c|c|c|c|c|c|c|c|c|c|c|c|c|c|c|c|c|}
\hline \multirow{2}{*}{$\begin{array}{l}\text { Growth } \\
\text { Stage DC }\end{array}$} & \multirow{2}{*}{$\begin{array}{c}\text { Nitrogen Status } \\
\text { Parameter }\end{array}$} & \multirow{2}{*}{$\begin{array}{c}\text { Reflectance } \\
\text { Index }\end{array}$} & \multicolumn{4}{|c|}{$\mathbf{a}$} & \multicolumn{4}{|c|}{ y0 } & \multicolumn{4}{|c|}{$R^{2}$} & \multicolumn{4}{|c|}{ RMSE } \\
\hline & & & 2011 & 2012 & 2013 & 2011-2013 & 2011 & 2012 & 2013 & 2011-2013 & 2011 & 2012 & 2013 & 2011-2013 & 2011 & 2012 & 2013 & 2011-2013 \\
\hline \multirow{9}{*}{ 29-31 } & \multirow{4}{*}{$\begin{array}{c}\mathrm{N} \text { content in } \\
\text { dry matter }(\%)\end{array}$} & NDVI & 4.72 & 7.95 & 0.56 & 1.38 & -1.34 & -3.45 & 2.54 & 1.77 & 0.29 & 0.46 & 0.04 & 0.08 & 0.375 & 0.458 & 0.317 & 0.464 \\
\hline & & NRERI & 3.29 & 9.59 & 2.29 & 3.14 & 0.97 & -2.19 & 1.84 & 1.21 & 0.39 & 0.6 & 0.13 & 0.23 & 0.346 & 0.393 & 0.302 & 0.424 \\
\hline & & SRPI & 1.82 & 4.38 & 0.51 & 1.55 & 1.35 & -0.63 & 2.57 & 1.64 & 0.35 & 0.46 & 0.06 & 0.2 & 0.359 & 0.457 & 0.314 & 0.433 \\
\hline & & NDVI & 4.07 & 3.37 & 1.34 & 1.38 & -2.89 & -1.89 & -0.29 & -0.37 & 0.72 & 0.64 & 0.73 & 0.4 & 0.128 & 0.133 & 0.096 & 0.169 \\
\hline & \multirow[t]{2}{*}{ NNI } & NRERI & 2.53 & 3.81 & 3.39 & 2.31 & -0.7 & -1.22 & -0.95 & -0.48 & 0.78 & 0.74 & 0.86 & 0.62 & 0.113 & 0.113 & 0.068 & 0.135 \\
\hline & & SRPI & 1.45 & 1.87 & 1.02 & 1.27 & -0.45 & -0.7 & -0.06 & -0.26 & 0.74 & 0.66 & 0.74 & 0.65 & 0.124 & 0.13 & 0.095 & 0.129 \\
\hline & \multirow{3}{*}{$\begin{array}{l}\mathrm{N} \text { uptake } \\
\left(\mathrm{kg} \mathrm{ha}^{-1}\right)\end{array}$} & NDVI & 609.5 & 408.1 & 205 & 206.9 & -478.9 & -253.9 & -97.8 & -103.9 & 0.76 & 0.68 & 0.8 & 0.47 & 17.409 & 14.777 & 12.1 & 21.997 \\
\hline & & NRERI & 375.4 & 448.1 & 508.9 & 335.2 & -150.4 & -166 & -192.9 & -113.7 & 0.81 & 0.74 & 0.91 & 0.68 & 15.587 & 13.272 & 8.279 & 17.017 \\
\hline & & SRPI & 216.3 & 229.2 & 157.5 & 185.7 & -114.9 & -112.2 & -62.9 & -83.8 & 0.77 & 0.71 & 0.83 & 0.73 & 17.01 & 14.041 & 11.326 & 15.602 \\
\hline \multirow{8}{*}{39} & \multirow{3}{*}{$\begin{array}{c}\mathrm{N} \text { content in } \\
\text { dry matter }(\%)\end{array}$} & NDVI & 0.23 & 6.69 & 4.81 & 3.41 & 1.52 & -3.75 & -2.07 & -1 & 0.01 & 0.55 & 0.16 & 0.18 & 0.182 & 0.302 & 0.334 & 0.385 \\
\hline & & NRERI & 0.37 & 5.13 & 3.48 & 2.23 & 1.5 & -0.89 & 0.11 & -0.68 & 0.04 & 0.59 & 0.25 & 0.17 & 0.179 & 0.287 & 0.315 & 0.386 \\
\hline & & SRPI & 0.24 & 2.37 & 2.08 & 1.67 & 1.54 & 0.06 & 0.4 & 0.62 & 0.05 & 0.58 & 0.29 & 0.36 & 0.178 & 0.29 & 0.306 & 0.339 \\
\hline & \multirow{3}{*}{ NNI } & NDVI & 1.83 & 3.14 & 5.02 & 2.47 & -1.01 & -2.03 & -3.84 & -1.52 & 0.66 & 0.69 & 0.64 & 0.5 & 0.081 & 0.104 & 0.113 & 0.128 \\
\hline & & NRERI & 1.24 & 2.39 & 3.04 & 1.68 & -0.15 & -0.67 & -1.19 & -0.34 & 0.75 & 0.73 & 0.71 & 0.53 & 0.07 & 0.097 & 0.1 & 0.125 \\
\hline & & SRPI & 0.68 & 1.09 & 1.73 & 0.97 & 0.08 & -0.22 & -0.85 & -0.14 & 0.72 & 0.71 & 0.75 & 0.67 & 0.074 & 0.101 & 0.093 & 0.105 \\
\hline & \multirow{2}{*}{$\begin{array}{l}\text { N uptake } \\
\left(\mathrm{kg} \mathrm{ha}^{-1}\right)\end{array}$} & NDVI & 452.3 & 477 & 949.2 & 460.4 & -326 & -333.1 & -784.7 & -330.3 & 0.76 & 0.74 & 0.75 & 0.6 & 15.745 & 13.976 & 16.425 & 19.546 \\
\hline & & SRPI & 164.5 & 164.6 & 312 & 149.9 & -52 & -57.7 & -206.1 & 14.4 & 0.78 & 0.75 & 0.8 & 0.66 & 15.01 & 13.721 & 14.499 & 18.203 \\
\hline
\end{tabular}




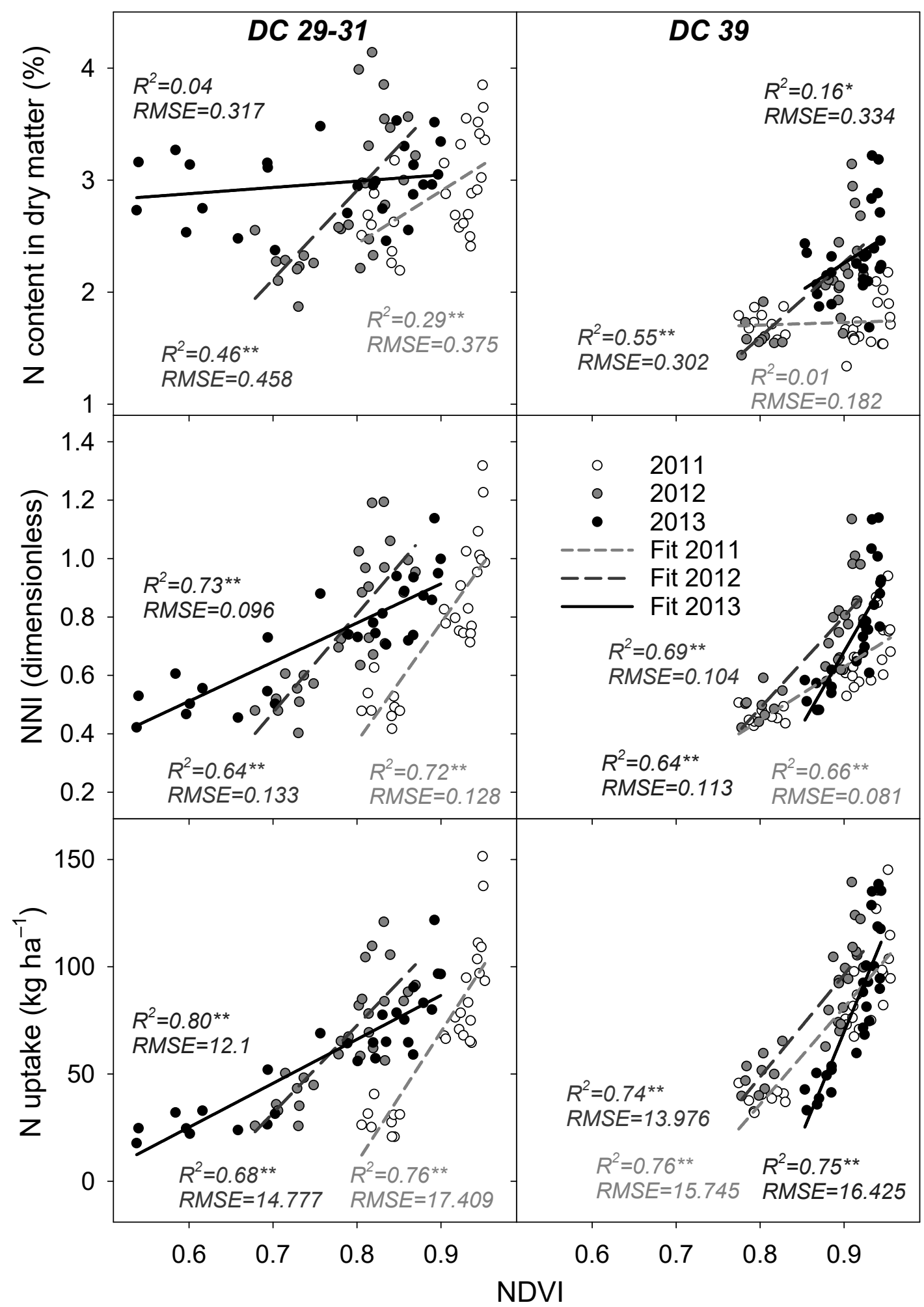

Figure 2. Linear relationships between vegetation index NDVI and nitrogen content in aboveground dry mass (upper), nitrogen nutrition index (NNI, middle), and nitrogen uptake by aboveground biomass per area unit (lower), analyzed separately for growth stage beginning of stem elongation (DC 29-31, left) and end of stem elongation (DC 39, right), and for individual years (2011—white points and light grey line, 2012-grey points and dark grey line, and 2013-black points and black line). Coefficients of determination $\left(R^{2}\right)$, root mean square errors (RMSE), and significant correlations $\left({ }^{*}\right.$ at $p<0.05$ and ${ }^{* *}$ at $\left.p<0.01\right)$ are indicated for each relationship. 


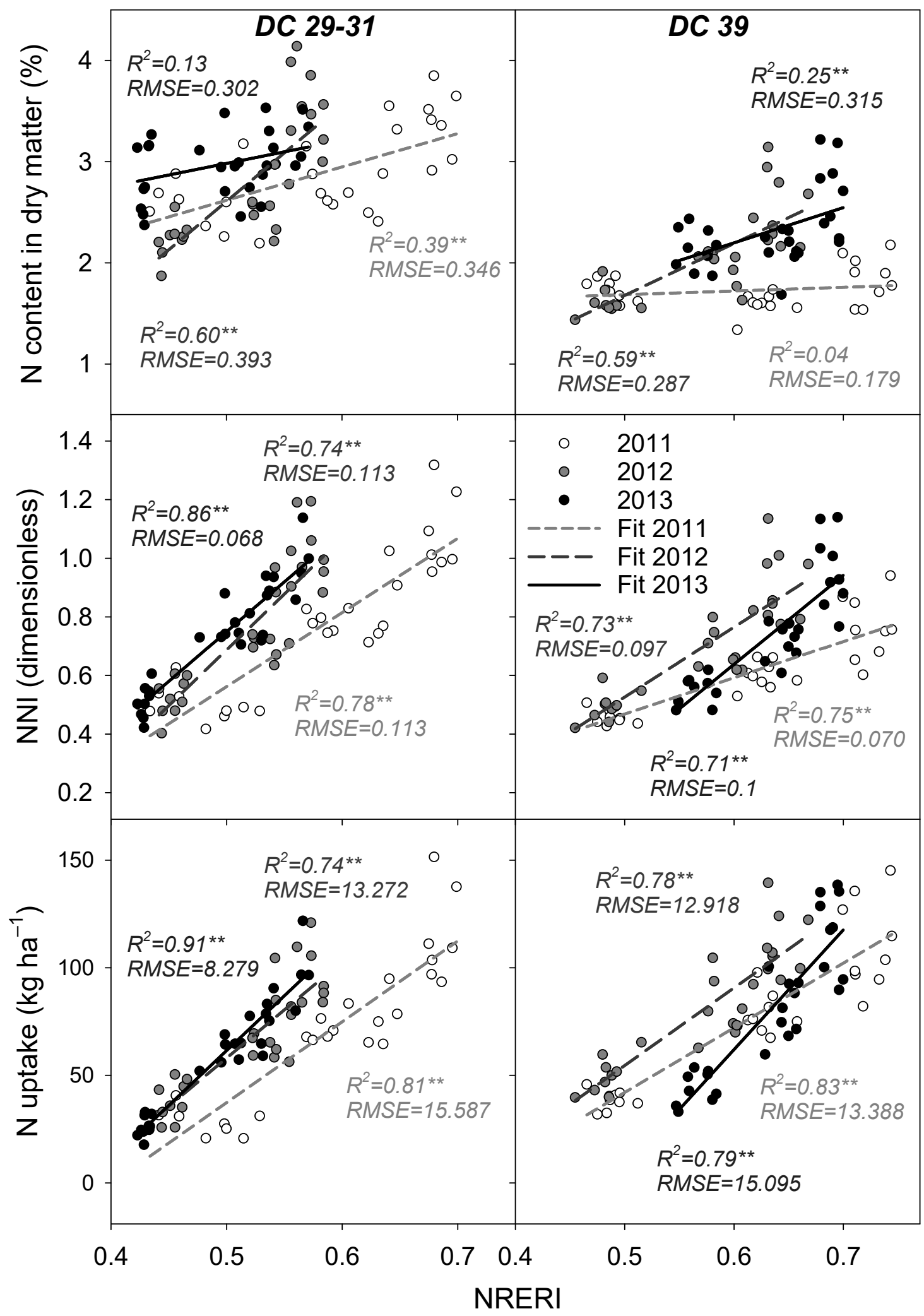

Figure 3. Linear relationships between reflectance index NRERI and nitrogen content in aboveground dry mass (upper), nitrogen nutrition index (NNI, middle), and nitrogen uptake by aboveground biomass per area unit (lower), analyzed separately for growth stage beginning of stem elongation (DC 29-31, left) and end of stem elongation (DC 39, right), and for individual years (2011—white points and light grey line, 2012-grey points and dark grey line, and 2013-black points and black line). Coefficients of determination $\left(R^{2}\right)$, root mean square errors (RMSE), and significant correlations $\left({ }^{*}\right.$ at $p<0.05$ and $^{* *}$ at $\left.p<0.01\right)$ are indicated for each relationship. 


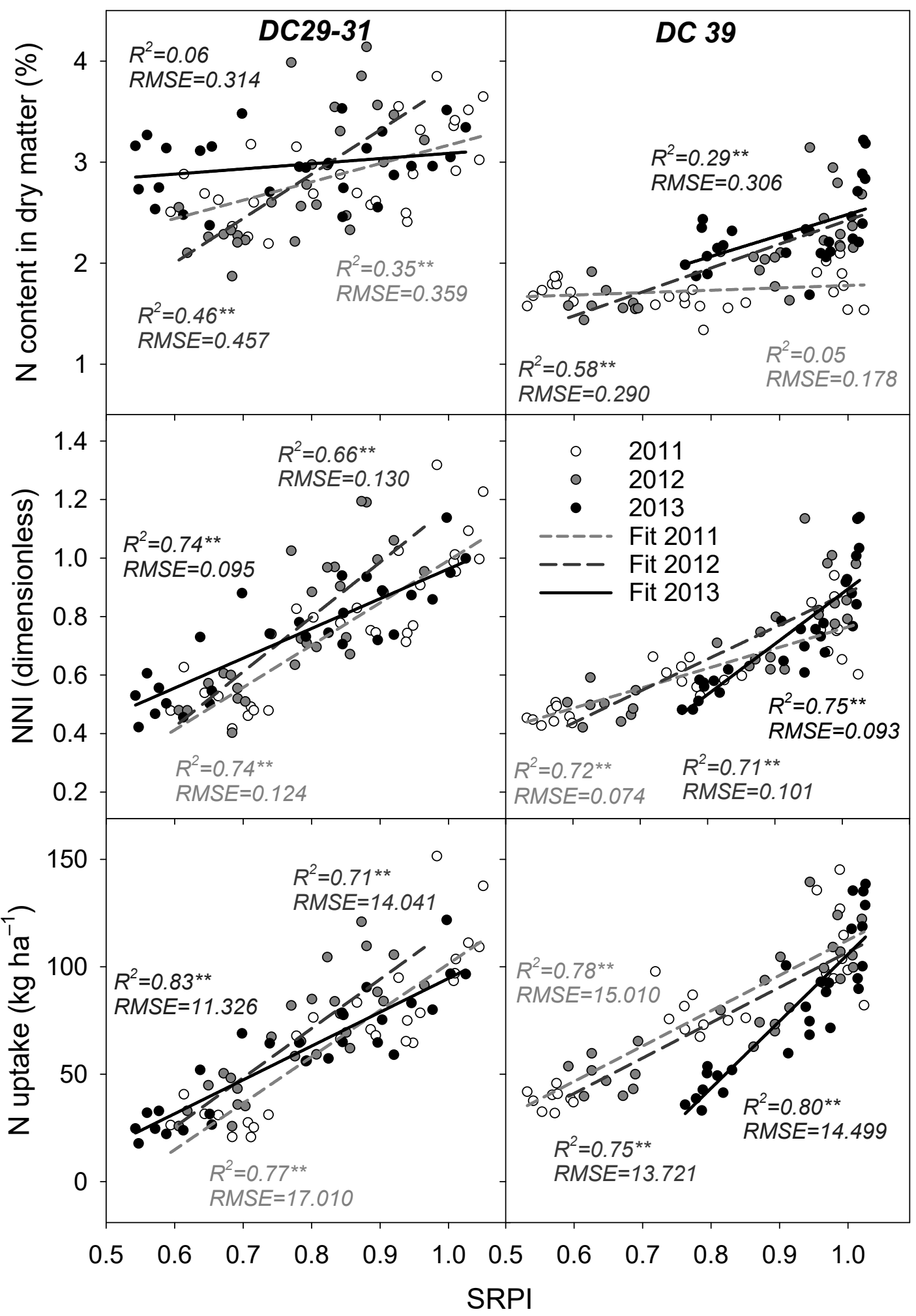

Figure 4. Linear relationships between reflectance index SRPI and nitrogen content in aboveground dry mass (upper), nitrogen nutrition index (NNI, middle), and nitrogen uptake by aboveground biomass per area unit (lower), analyzed separately for growth stage beginning of stem elongation (DC 29-31, left) and end of stem elongation (DC 39, right), and for individual years (2011—white points and light grey line, 2012-grey points and dark grey line, and 2013-black points and black line). Coefficients of determination $\left(R^{2}\right)$, root mean square errors (RMSE), and significant correlations $\left({ }^{*}\right.$ at $p<0.05$ and ${ }^{* *}$ at $\left.p<0.01\right)$ are indicated for each relationship. 


\subsection{Relationships between Indicators of N Status and Grain Yield}

The relationships between indicators of nutritional status (i.e., $\mathrm{N}$ content in aboveground dry matter, NNI index, and N uptake per area unit) and grain yield achieved were evaluated separately for each year (Figure 5). Generally, these relationships exhibit a rectangular hyperbola shape, although it is evident that in some cases, the upper asymptote was not reached. The greatest variation in relationships was observed for the $\mathrm{N}$ content in dry matter. While in 2013, there was almost no correlation between N content and yield, in 2011, a very steep and significant relationship without reaching the upper asymptote was found. In 2012, the typical rectangular hyperbola relationship was observed. Conversely, the relationships between NNI and N uptake per area unit showed the rectangular hyperbola course in virtually all combinations of year and growth stage. At the same time, the shape of the relationship changed only a little, but the upper asymptote changed significantly between years. This means that the maximum yield is generally obtained in all years at the same level of nutritional status, whether it is defined as NNI or N uptake. For NNI, the maximum yield was achieved at values just above 1.0 in both growth stages, whereas for $\mathrm{N}$ uptake, a slight shift of the maximum was found. The yield maximum was reached at $\mathrm{N}$ uptake of about 100 and $120 \mathrm{~kg} \mathrm{~N} \mathrm{ha}^{-1}$ in growth stage DC 29-31 and DC 39, respectively.

\subsection{Artificial Neural Networks Based on Hyperspectral Data for Estimating N Status}

For purposes of training neural networks, it was first necessary to reduce the initial reflectance dataset to optimize the range of the input variables. Reflectance data were first reduced by using the $10 \mathrm{~nm}$ step and in the range $380-850 \mathrm{~nm}$. Subsequently, principal component analysis (PCA) was used to select only the reflectance wavelengths with major explanatory importance for indicators of $\mathrm{N}$ status. In total, 17 reflectance wavelengths with the highest PCA scores (components 1 and 2), and also minimum differential angle (or close to $180^{\circ}$ for negative association) to the PCA loadings for $\mathrm{N}$ status indicators, were selected for subsequent neural network training. The set of 162 observations was randomly divided into training (114 observations), test, and validation (each with 24 observations) datasets. From 10,000 trained networks for each combination of $\mathrm{N}$ status indicator and growth stage, a set of 10 networks was chosen for each training set $(\mathrm{N}$ status indicator and growth stage combination), having the lowest training and validation error and highest $R^{2}$ for the relationship between predicted and observed values. These networks were subjected to 50 training cycles with new random dividing on training, test, and validation datasets for each. The network showing the lowest variation between training cycles was then selected as the best network. If the variation of performance during 50 training cycles was higher than $25 \%$, the process was repeated. The scatterplots of predicted and observed data for best networks and their comparison with the 1:1 line are shown in Figure 6. It is evident from these results that neural networks substantially enable elimination of interannual variability, and therefore significantly improve the accuracy of $\mathrm{N}$ status estimation. This is especially the case for $\mathrm{N}$ content in the dry aboveground biomass. While for the best of vegetation indices-SRPI- $R^{2}$ values of 0.2 and 0.36 had been achieved in the growth stages DC 29-31 and 39, respectively, through the use of neural networks, $R^{2}$ was increased to 0.75 and 0.8 , respectively. For NNI index and N uptake, the $R^{2}$ value increased from the range $0.58-0.73$ for the best vegetation indices to $0.83-0.87$ when using neural networks. An overview of the best neural networks, their performance in the training, test, and validation dataset, and also the activation functions used for each estimated parameter of $\mathrm{N}$ status and growth stage are shown in Table 4 . A sensitivity analysis describing the explanatory value of reflectance in each individual wavelength for the neural network model is shown in Supplementary Table S2. It is noteworthy that the reflectance wavelength with the highest sensitivity ranking differs substantially between estimated $\mathrm{N}$ status parameters and also between growth stages. 

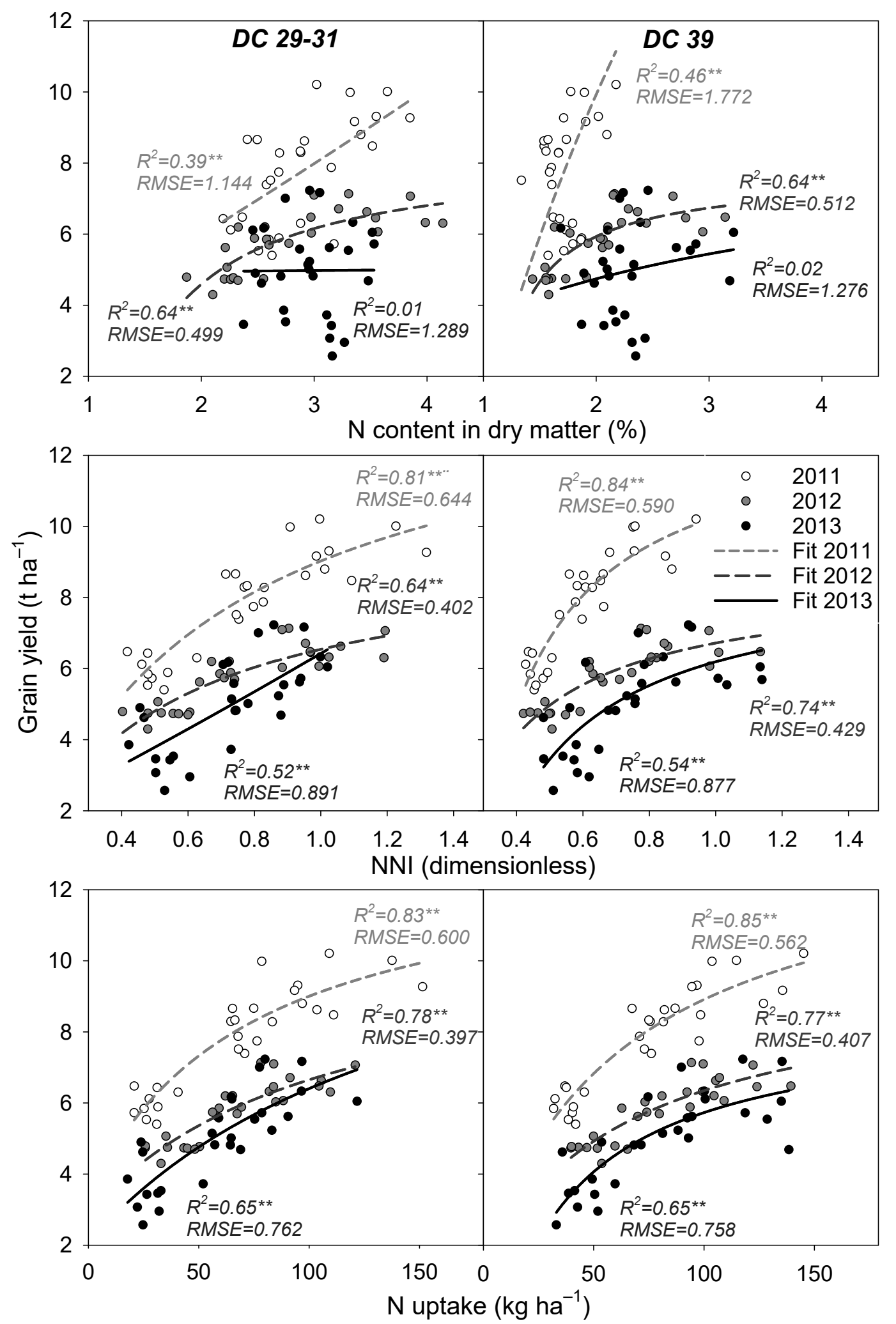

Figure 5. Rectangular hyperbola relationships between nitrogen content in aboveground dry mass (upper), nitrogen nutrition index (NNI, middle), nitrogen uptake by aboveground biomass per area unit (lower) and grain yield, analyzed separately for growth stage beginning of stem elongation (DC 29-31, left) and end of stem elongation (DC 39, right), and for individual years (2011—white points and light grey line, 2012-grey points and dark grey line, and 2013-black points and black line). Coefficients of determination $\left(R^{2}\right)$, root mean square error (RMSE), and significant correlations $\left({ }^{*}\right.$ at $p<0.05$ and ${ }^{* *}$ at $\left.p<0.01\right)$ are indicated for each relationship. 

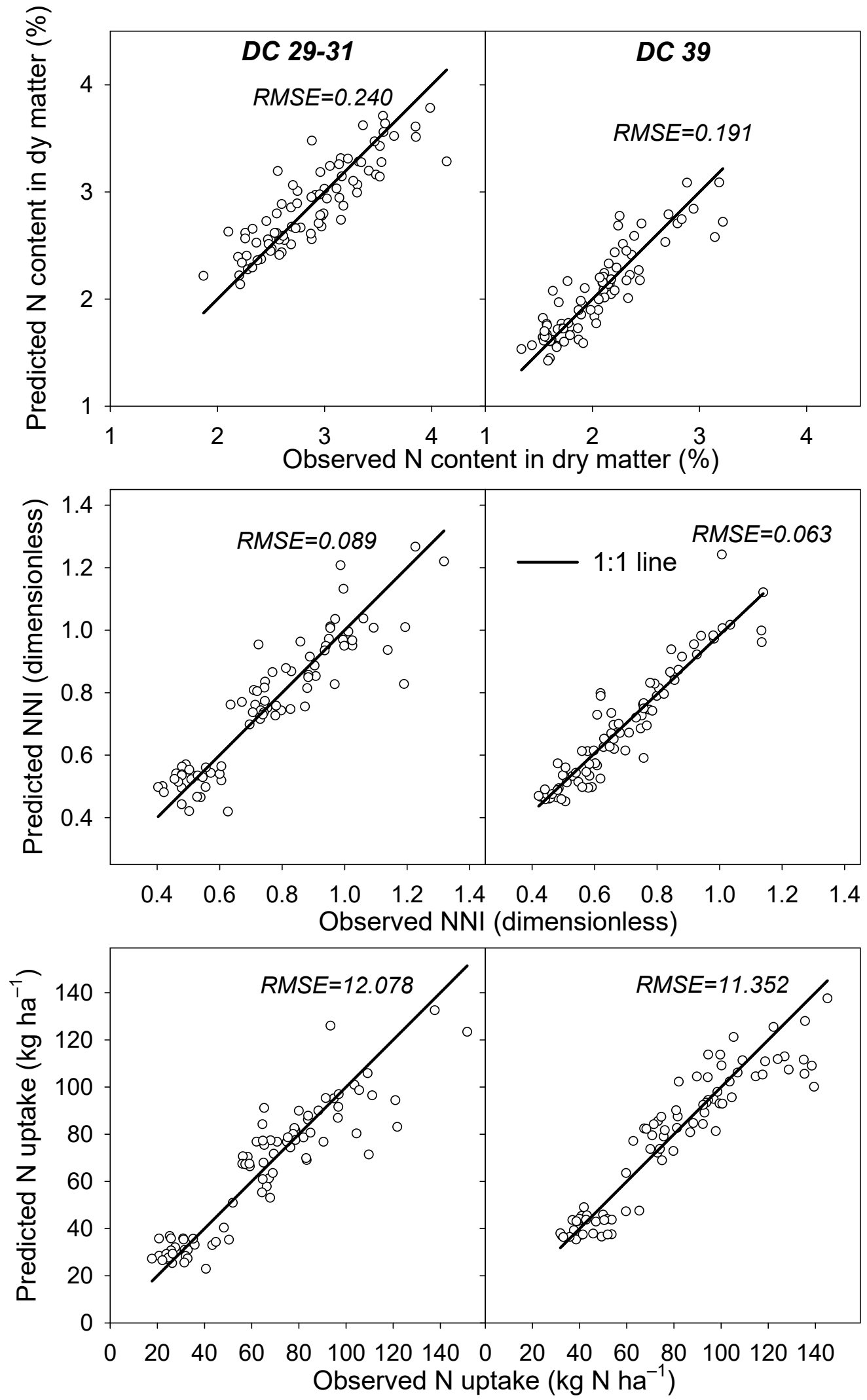

Figure 6. Comparison of observed nitrogen content in aboveground dry mass (upper), nitrogen nutrition index (NNI, middle), and nitrogen uptake by aboveground biomass per area unit (lower) with predicted values by winning artificial neural networks. The 1:1 lines are plotted to evaluate deviations from observed data. Root mean square errors (RMSE) are indicated for each predicted set of data. 
Table 4. Characteristics and performance of winning neural networks (MLP-multilayer perceptron) for estimation of individual nitrogen status parameters at growth stage DC 29-31 and DC 39. Network performance is given separately for training, test and validation datasets. Exponential, logistic, and hyperbolic tangent activation functions (TanH) are indicated for the hidden and output layer of the neural network.

\begin{tabular}{cccccccc}
\hline & & & \multicolumn{2}{c}{ Network Performance } & \multicolumn{2}{c}{ Activation Function } \\
\hline $\begin{array}{c}\text { Growth } \\
\text { Stage }\end{array}$ & Estimated Parameter & $\begin{array}{c}\text { Network } \\
\text { Name }\end{array}$ & Training & Test & Validation & Hidden & Output \\
\hline & N content in dry matter (\%) & MLP 17-15-1 & 0.897 & 0.753 & 0.923 & TanH & TanH \\
DC 29-31 & NNI & MLP 17-8-1 & 0.927 & 0.856 & 0.938 & Exponential & TanH \\
& N uptake $\left(\mathrm{kg} \mathrm{ha}^{-1}\right)$ & MLP 17-11-1 & 0.920 & 0.877 & 0.958 & Exponential & Logistic \\
& N content in dry matter (\%) & MLP 17-13-1 & 0.924 & 0.887 & 0.883 & TanH & Logistic \\
DC 39 & NNI & MLP 17-6-1 & 0.955 & 0.950 & 0.950 & TanH & Exponential \\
& N uptake $\left(\mathrm{kg} \mathrm{ha}^{-1}\right)$ & MLP 17-12-1 & 0.922 & 0.975 & 0.965 & TanH & Exponential \\
\hline
\end{tabular}

\section{Discussion}

The $\mathrm{N}$ status of malting barley requires relatively precise optimization because nitrogen deficiency leads, in particular, to reduced tillering and impaired yield formation. On the other hand, the $\mathrm{N}$ excess causes an increase in grain protein content, aggravating the malting quality, but it also leads to increased lodging and associated adverse effects such as yield reduction or mycotoxin contamination [6,7]. From the economic point of view, the impact of $\mathrm{N}$ nutrition on grain protein content is crucial. Although it also depends on a number of other factors, such as sufficient water availability and optimum temperature, it significantly impacts the price and economics of malting barley production. Water stress and excessive temperatures limit starch accumulation more than nitrogen translocation, resulting in higher grain protein content, while under sufficient water availability is the grain protein content, transformed from translocated N, diluted in higher starch accumulation [23]. Although environmental conditions can significantly modulate the translation of $\mathrm{N}$ status into grain protein content and should always be carefully considered when making decisions about $\mathrm{N}$ nutrition in malting barley, $\mathrm{N}$ status is still one of the most critical parameters for the final grain protein content that can be affected by agronomic practices. Therefore, accurate and reliable methods of $\mathrm{N}$ status monitoring during vegetation are required to achieve the malting quality of grain needed.

The main objective of this study was to improve the estimation of $\mathrm{N}$ status in malting barley using hyperspectral data, and in particular, to eliminate the sources of variability given by the effect of year, canopy structure, and genotype, doing so through the use of more robust reflectance indices, $\mathrm{N}$ status indicators, and, finally, by using artificial neural networks.

\subsection{Hyperspectral Estimation of NNI}

The $\mathrm{N}$ nutrition index (NNI) was introduced to assess the relative $\mathrm{N}$ status with respect to rapidly changing $\mathrm{N}$ content in plant biomass during plant development, which is characterized by the so-called critical or dilution curve [20]. $\mathrm{N}$ dilution is caused by a gradual change in the ratio between metabolic and structural tissues in favor of structural tissues, which contain much less N [24]. NNI represents the ratio between actual and critical $\mathrm{N}$ content and indicates the relative value of actual $\mathrm{N}$ status compared to minimum $\mathrm{N}$ content for maximum biomass or yield production [20]. The main advantage of using NNI to assess N nutrition status is that it provides an objective parameter that is comparable throughout the entire vegetation season, irrespective of growth stage and biomass accumulation. An NNI value greater than 1 indicates N surplus, and an NNI value less than 1 points to $\mathrm{N}$ deficiency. Although NNI is an effective tool in terms of increasing the accuracy and simplifying the assessment of $\mathrm{N}$ status, it has rarely been used for estimating $\mathrm{N}$ status from hyperspectral data. One of the first studies within which NNI was estimated in winter wheat using the red edge inflexion point (REIP) spectral 
reflectance index was published by Mistele and Schmidhalter [25]. They also showed the effects of year and growth stage on the relationship between REIP and NNI. Especially at early growth stages, the relationship differs from the typical relationship found after canopy closure. Houles et al. [26] also showed that NNI corresponds to the N status of the whole canopy rather than to actual $\mathrm{N}$ or chlorophyll content at the leaf level, which can explain some differences due to canopy development. We achieved similar results within the present study. While the relationships between vegetation indices and $\mathrm{N}$ content in the aboveground dry matter were generally weak and highly variable between years, for NNI, close relationships were found that varied only a little between years. The $R^{2}$ values for relationships between NNI and vegetation indices were approximately three times higher than those determined for relationships between the indices and $\mathrm{N}$ content in the aboveground dry matter (Table 3, Figures 2-4). However, the relationships to NNI showed an effect of growth stage on both intercept and slope of relationship, indicating that NNI cannot completely decouple the effect of biomass and leaf area even for the best vegetation indices.

Later, Erdle et al. [27] demonstrated that significantly more accurate estimation of the $\mathrm{N}$ nutrition status by spectral reflectance is achieved using NNI in comparison with the detection of N content in plants. Generally, the best estimate of NNI was achieved using indices based on the red-edge band reflectance, and in particular, using the REIP index. Chen et al. [28] introduced a new spectral index based on red-edge, known as the double-peak canopy $\mathrm{N}$ index (DCNI), for improved estimation of $\mathrm{N}$ content as input for NNI calculation. Such indirect estimation of NNI requires, however, the knowledge of biomass that may increase the estimation error because it is necessary to estimate two parameters showing interactions in their effects on spectral reflectance. Our results, too, showed a reliable estimation of NNI using spectral indices based on the red-edge band (NRERI, ANMB ${ }_{650-725}, \mathrm{ZM}$; Table 2, Figure 3). Even better results, however, were achieved for indices employing reflectance at $430 \mathrm{~nm}\left(\mathrm{R}_{430}\right.$; $\mathrm{SRPI}$ and NPCI; Table 2, Figure 4). These indices are mostly related to the ratio between total carotenoids and chlorophylls [29]. Although the correlation matrix for NNI (Figure 1) shows that the sensitive area in the blue reflectance region narrows with the growth stage, the correlation for reflectance indices based on $\mathrm{R}_{430}$ is almost not changed with the growth stage (Table 1 ). The sensitivity to $\mathrm{N}$ status of reflectance indices based on $R_{430}$ had been shown already by Filella et al. [30]. $\mathrm{N}$ deficiency generally increases the total carotenoids and chlorophylls ratio because carotenoids persist longer than do chlorophylls in senescing leaves [31], and $\mathrm{N}$ deficit induces leaf senescence [32].

Based on our results, direct estimation of NNI using spectral reflectance appears to be more accurate than the separate estimation of $\mathrm{N}$ content and plant biomass, even though the relationship is slightly modified by the growth stage. On the contrary, the relationships for $\mathrm{N}$ content in aboveground dry biomass show variation in slope and $R^{2}$ between both growth stages and years, probably due to the rapid dilution of $\mathrm{N}$ in biomass. This leads to a significant decrease of $R^{2}$ if the data are analyzed across years, and even more so if performed across growth stages. Conversely, only small changes in $R^{2}$ were observed when such data were analyzed for NNI. The use of calibration, even in the case of NNI, however, may be beneficial for improving estimation accuracy.

\subsection{Hyperspectral Estimation of N Uptake by Aboveground Biomass}

Optimization of $\mathrm{N}$ nutrition based upon total $\mathrm{N}$ uptake is, in principle, a simpler method than evaluating NNI, and it also has some practical advantages. These lie particularly in the possibility to optimize $\mathrm{N}$ nutrition on the basis of total $\mathrm{N}$ balance for expected yield and grain protein content, the latter of which is one of the key grain quality parameters for malting barley. $\mathrm{N}$ uptake can also be relatively easily estimated by spectral reflectance with the best estimation performance of the normalized red-edge index [33]. Similarly, Erdle et al. [27] demonstrated the best performance for the simple ratio index based on red-edge reflectance for estimation of both NNI and N uptake. This is in line with 
our results showing a good estimation of $\mathrm{N}$ uptake by red-edge indices NRERI, ZM, or $\mathrm{ANMB}_{650-725}$. On the other hand, $\mathrm{N}$ uptake does not enable direct estimation of relative $\mathrm{N}$ status, which requires comparison with optimum $\mathrm{N}$ uptake for a given growth stage or biomass. This can be derived from the critical $\mathrm{N}$ curve as a critical $\mathrm{N}$ uptake [34], but it requires knowledge of biomass production. In our study, estimation of $\mathrm{N}$ uptake by aboveground biomass using spectral reflectance generally had significantly higher accuracy than did the estimation of $\mathrm{N}$ content, and it also slightly outperformed the estimation of $\mathrm{N}$ status by NNI. This is due to the fact that $\mathrm{N}$ uptake per unit area integrates the effects both of biomass and of $\mathrm{N}$ content in dry matter. Higher $\mathrm{N}$ uptake may be given by higher biomass production at the same $\mathrm{N}$ content or by higher $\mathrm{N}$ content at the same biomass production. However, actual $\mathrm{N}$ uptake at the given stage can be compared with optimum uptake for required yield without any information about biomass production.

In earlier studies in winter wheat, it was demonstrated that $\mathrm{N}$ optimization could be successfully carried out on the basis of remote sensing estimation of early-season $\mathrm{N}$ uptake and estimation of grain yield potential $[35,36]$. These optimization algorithms were based on NDVI estimation between the end of tillering and the beginning of stem elongation, and the yield potential was estimated as NDVI divided by growing degree days. Such estimation of yield potential can also be useful in spring barley, as the NDVI show particularly higher values at the high yielding year 2011 when evaluated at the early growth stage (DC 29-31) even for the same N uptake levels. On the other hand, SRPI can be used to estimate the $\mathrm{N}$ uptake without the effect of yield potential. Optimum $\mathrm{N}$ dose can thus be derived from yield potential (and optimal $\mathrm{N}$ uptake for such yield) estimated from NDVI and actual $\mathrm{N}$ uptake estimated from SRPI. The maximum yield for a given $\mathrm{N}$ response curve is limited mainly by genotype and environment/year [37]. As demonstrated in our recent work [3], the yield potential of spring barley is determined in the early growth stages up to the beginning of stem elongation (DC 31), which supports the idea of early estimation of yield potential from NDVI for N dose optimization.

\subsection{Artificial Neural Network for Estimating N Status Using Hyperspectral Data}

The application of artificial neural networks has, in recent decades, become rather popular in the analysis of remotely sensed data [38]. The most common applications are in image processing, particularly as classification algorithms (e.g., for land-cover classification). Artificial neural networks also have been applied to retrieve biophysical parameters of vegetation. For example, Bacour et al. [39] developed neural network algorithms for estimating leaf area index, canopy chlorophyll content, and absorbed photosynthetically active radiation, Liu et al. [40] used neural networks to discriminate fungal infection in rice panicles from hyperspectral reflectance, and Christensen et al. [41] adopted neural network for classification of barley growth stage from hyperspectral data.

In our study, we demonstrated the considerable potential of artificial neural networks for improving the direct estimation of $\mathrm{N}$ content in barley aboveground biomass from hyperspectral data in comparison with best spectral reflectance indices. The neural network model reduces not only the variability within one year given by genotype or sowing density but also the interannual variation, which is a much more important source of inaccuracy. The effect of year changes both intercepts and slopes of relationships between spectral reflectance indices and $\mathrm{N}$ content. A similar improvement of $\mathrm{N}$ content estimation by the artificial neural network, compared to the linear regression model, was reported for rice by Yi et al. [42]. They also demonstrated that both multiple linear regression and principal component analysis were suitable to select input variables for neural network training. Wang et al. [43] demonstrated the strength of neural network predictions in comparison with stepwise regression for $\mathrm{N}$ content in rape. Recently, Sun et al. [44] showed that the neural network provided the best performance in estimating $\mathrm{N}$ content in rice from both active and passive reflectance sensors.

The employment of artificial neural networks in remote sensing provides a number of advantages in comparison to regression models [45]. First, the neural network allows the 
development of complex models with multiple input parameters and by employing diverse nonlinear response functions. Secondly, neural networks allow combining different types of input data, including categorical ones and thus improving the model by introducing the data, e.g., regarding the preceding crop, soil, genotype, weather, etc. Finally, high adaptivity, given by the possibility to retrain the model on the new dataset, is of significant advantage if the model is used in new conditions. Neural networks also allow joint estimation of multiple biophysical and biochemical variables [39].

\section{Conclusions}

We demonstrated that the use of indirect $\mathrm{N}$ status indicators, such as NNI or N uptake per ground area unit, could significantly improve the estimation accuracy from spectral reflectance data, compared to $\mathrm{N}$ content in dry aboveground biomass. From spectral reflectance indices tested, the red-edge indices (NRERI, ZM, or $\mathrm{ANMB}_{650-725}$ ) and carotenoid indices (SRPI and NPCI) showed the lowest interannual variability. Although the maximum yield varied significantly between years, the NNI and N uptake estimated by spectral reflectance may be used in both growth stages as accurate estimators of $\mathrm{N}$ status in malting barley. The use of the artificial neural network for $\mathrm{N}$ status estimation from hyperspectral data reduced both intra- and interannual variability significantly and provided estimation accuracy above $90 \%$. A more than the twofold increase of estimation accuracy with the use of a neural network model was found for $\mathrm{N}$ content in aboveground dry mass. Although the significance of individual wavelength varied with the $\mathrm{N}$ status indicator and growth stage, the key reflectance bands for most neural network models were around 430, 530, and $710 \mathrm{~nm}$.

Supplementary Materials: The following are available online at https:/ /www.mdpi.com/article/10 .3390 /agronomy11122592/s1, Table S1: List of vegetation indices used in correlation analyses with nitrogen status parameters, equations for their calculation from reflectances in given wavelength ( $R_{x}$ is the reflectance in wavelength $x \mathrm{~nm}$ ), and the references for each index. Table S2: Sensitivity analysis for individual input reflectance wavelength in winning neural networks for estimation of nitrogen status parameters.

Author Contributions: Conceptualization, J.K., K.K. and P.M.; methodology, P.M., J.K., K.K., I.S. and V.L.; formal analysis, K.K., D.K., J.Š. and H.F.; investigation, K.K., I.S., P.M., J.K. and V.L.; data curation, K.K., P.M., P.H., D.K., H.F. and J.Š.; writing—original draft preparation, K.K., J.K., P.M., P.L., P.H. and O.U.; writing—review and editing, O.U., P.H., K.K., P.L., J.Š., P.M. and J.K.; visualization, D.K., K.K., P.H. and P.L.; supervision, J.K. All authors have read and agreed to the published version of the manuscript.

Funding: This research was funded by the grant agency of the Ministry of Agriculture of the Czech Republic (NAZV) project number QK1910197. J.Š. was funded by the internal grant agency of Mendel University in Brno project number AF-IGA2019-IP043. K.K., D.K., P.H., P.L., H.F. and O.U. were funded by the project SustES "Adaptation strategies for sustainable ecosystem services and food security under adverse environmental conditions" (CZ.02.1.01/0.0/0.0/16_019/0000797).

Data Availability Statement: Data is contained within the article.

Conflicts of Interest: The authors declare no conflict of interest.

\section{References}

1. Weston, D.T;; Horsley, R.D.; Schwarz, P.B.; Goos, R.J. Nitrogen and Planting Date Effects on Low-Protein Spring Barley. Agron. J. 1993, 85, 1170-1174. [CrossRef]

2. Baethgen, W.E.; Christianson, C.B.; Lamothe, A.G. Nitrogen fertiliser effects on growth, grain yield, and yield components of malting barley. Field Crop. Res. 1995, 43, 87-99. [CrossRef]

3. Křen, J.; Klem, K.; Svobodová, I.; Míša, P.; Neudert, L. Yield and grain quality of spring barley as affected by biomass formation at early growth stages. Plant Soil Environ. 2014, 60, 221-227. [CrossRef]

4. Edney, M.J.; O’Donovan, J.T.; Turkington, T.K.; Clayton, G.W.; McKenzie, R.; Juskiw, P.; Lafond, G.P.; Brandt, S.; Grant, C.A.; Harker, K.N.; et al. Effects of seeding rate, nitrogen rate and cultivar on barley malt quality. J. Sci. Food Agric. 2012, 92, 2672-2678. [CrossRef] [PubMed] 
5. Hansen, P.M.; Jørgensen, J.R.; Thomsen, A. Predicting grain yield and protein content in winter wheat and spring barley using repeated canopy reflectance measurements and partial least squares regression. J. Agric. Sci. 2002, 139, 307-318. [CrossRef]

6. Langseth, W.; Stabbetorp, H. The effect of lodging and time of harvest on deoxynivalenol contamination in barley and oats. J. Phytopathol. 1996, 144, 241-245. [CrossRef]

7. Nakajima, T.; Yoshida, M.; Tomimura, K. Effect of lodging on the level of mycotoxins in wheat, barley, and rice infected with the Fusarium graminearum species complex. J. Gen. Plant Pathol. 2008, 74, 289. [CrossRef]

8. Olfs, H.W.; Blankenau, K.; Brentrup, F.; Jasper, J.; Link, A.; Lammel, J. Soil- and plant-based nitrogen-fertiliser recommendations in arable farming. J. Plant Nutr. Soil Sci. 2005, 168, 414-431. [CrossRef]

9. Hatfield, J.L.; Gitelson, A.A.; Schepers, J.S.; Walthall, C.L. Application of spectral remote sensing for agronomic decisions. Agron. J. 2008, 100, S-117-S-131. [CrossRef]

10. Chen, P. A Comparison of Two Approaches for Estimating the Wheat Nitrogen Nutrition Index Using Remote Sensing. Remote Sens. 2015, 7, 4527-4548. [CrossRef]

11. Yoder, B.J.; Pettigrew-Crosby, R.E. Predicting nitrogen and chlorophyll content and concentrations from reflectance spectra (400-2500 nm) at leaf and canopy scales. Remote Sens. Environ. 1995, 53, 199-211. [CrossRef]

12. Merzlyak, M.N.; Gitelson, A.A. Why and what for the leaves are yellow in autumn? On the interpretation of optical spectra of senescing leaves (Acerplatanoides L.). J. Plant Physiol. 1995, 145, 315-320. [CrossRef]

13. Buschmann, C.; Nagel, E. In vivo spectroscopy and internal optics of leaves as basis for remote sensing of vegetation. Int. J. Remote Sens. 1993, 14, 711-722. [CrossRef]

14. Clevers, J.G.P.W.; Gitelson, A.A. Remote estimation of crop and grass chlorophyll and nitrogen content using red-edge bands on Sentinel-2 and -3. Int. J. Appl. Earth Obs. 2013, 23, 344-351. [CrossRef]

15. Schlemmer, M.; Gitelson, A.A.; Schepers, J.; Ferguson, R.; Peng, Y.; Shanahan, J.; Rundquist, D. Remote estimation of nitrogen and chlorophyll contents in maise at leaf and canopy levels. Int. J. Appl. Earth Obs. 2013, 25, 47-54. [CrossRef]

16. Sembiring, H.; Lees, H.L.; Raun, W.R.; Johnson, G.V.; Solie, J.B.; Stone, M.L.; DeLeon, M.J.; Lukina, E.V.; Cossey, D.A.; LaRuffa, J.M.; et al. Effect of growth stage and variety on spectral radiance in winter wheat. J. Plant Nutr. 2000, 23, 141-149. [CrossRef]

17. Aparicio, N.; Villegas, D.; Araus, J.L.; Casadesús, J.; Royo, C. Relationship between growth traits and spectral vegetation indices in durum wheat. Crop Sci. 2002, 42, 1547-1555. [CrossRef]

18. Hansen, P.M.; Schjoerring, J.K. Reflectance measurement of canopy biomass and nitrogen status in wheat crops using normalised difference vegetation indices and partial least squares regression. Remote Sens. Environ. 2003, 86, 542-553. [CrossRef]

19. Li, F.; Miao, Y.; Hennig, S.D.; Gnyp, M.L.; Chen, X.; Jia, L.; Bareth, G. Evaluating hyperspectral vegetation indices for estimating nitrogen concentration of winter wheat at different growth stages. Precis. Agric. 2010, 11, 335-357. [CrossRef]

20. Lemaire, G.; Jeuffroy, M.H.; Gastal, F. Diagnosis tool for plant and crop N status in vegetative stage: Theory and practices for crop N management. Eur. J. Agron. 2008, 28, 614-624. [CrossRef]

21. Gastal, F.; Lemaire, G. N uptake and distribution in crops: An agronomical and ecophysiological perspective. J. Exp. Bot. 2002, 53, 789-799. [CrossRef]

22. Mouazen, A.M.; Kuang, B.; De Baerdemaeker, J.; Ramon, H. Comparison among principal component, partial least squares and back propagation neural network analyses for accuracy of measurement of selected soil properties with visible and near infrared spectroscopy. Geoderma 2010, 158, 23-31. [CrossRef]

23. Savin, R.; Nicolas, M.E. Effects of short periods of drought and high temperature on grain growth and starch accumulation of two malting barley cultivars. Funct. Plant Biol. 1996, 23, 201-210. [CrossRef]

24. Lemaire, G.; Gastal, F. N uptake and distribution in plant canopies. In Diagnosis of the Nitrogen Status in Crops; Springer: Berlin/Heidelberg, Germany, 1997; pp. 3-43.

25. Mistele, B.; Schmidhalter, U. Estimating the nitrogen nutrition index using spectral canopy reflectance measurements. Eur. J. Agron. 2008, 29, 184-190. [CrossRef]

26. Houlès, V.; Guérif, M.; Mary, B. Elaboration of a nitrogen nutrition indicator for winter wheat based on leaf area index and chlorophyll content for making nitrogen recommendations. Eur. J. Agron. 2007, 27, 1-11. [CrossRef]

27. Erdle, K.; Mistele, B.; Schmidhalter, U. Comparison of active and passive spectral sensors in discriminating biomass parameters and nitrogen status in wheat cultivars. Field Crop. Res. 2011, 124, 74-84. [CrossRef]

28. Chen, P.; Haboudane, D.; Tremblay, N.; Wang, J.; Vigneault, P.; Li, B. New spectral indicator assessing the efficiency of crop nitrogen treatment in corn and wheat. Remote Sens. Environ. 2010, 114, 1987-1997. [CrossRef]

29. Peñuelas, J.; Baret, F.; Filella, I. Semi-empirical indices to assess carotenoids/chlorophyll a ratio from leaf spectral reflectance. Photosynthetica 1995, 31, 221-230.

30. Filella, I.; Serrano, L.; Serra, J.; Peñuelas, J. Evaluating wheat nitrogen status with canopy reflectance indices and discriminant analysis. Crop Sci. 1995, 35, 1400-1405. [CrossRef]

31. Hörtensteiner, S. Chlorophyll degradation during senescence. Annu. Rev. Plant Biol. 2006, 57, 55-77. [CrossRef] [PubMed]

32. Agüera, E.; Cabello, P.; De La Haba, P. Induction of leaf senescence by low nitrogen nutrition in sunflower (Helianthus annuus) plants. Physiol. Plant. 2010, 138, 256-267. [CrossRef] [PubMed]

33. Magney, T.S.; Eitel, J.U.H.; Vierling, L.A. Mapping wheat nitrogen uptake from RapidEye vegetation indices. Precis. Agric. 2017, 18, 429-451. [CrossRef] 
34. Sadras, V.O.; Lemaire, G. Quantifying crop nitrogen status for comparisons of agronomic practices and genotypes. Field Crop. Res. 2014, 164, 54-64. [CrossRef]

35. Lukina, E.V.; Freeman, K.W.; Wynn, K.J.; Thomason, W.E.; Mullen, R.W.; Stone, M.L.; Solie, J.B.; Klatt, A.R.; Johnson, G.V.; Elliott, R.L.; et al. Nitrogen fertilisation optimisation algorithm based on in-season estimates of yield and plant nitrogen uptake. J. Plant Nutr. 2001, 24, 885-898. [CrossRef]

36. Raun, W.R.; Solie, J.B.; Johnson, G.V.; Stone, M.L.; Mullen, R.W.; Freeman, K.W.; Thomason, W.E.; Lukina, E.V. Improving Nitrogen Use Efficiency in Cereal Grain Production with Optical Sensing and Variable Rate Application. Agron. J. 2002, 94, 815-820. [CrossRef]

37. Lawlor, D.W. Carbon and nitrogen assimilation in relation to yield: Mechanisms are the key to understanding production systems. J. Exp. Bot. 2002, 53, 773-787. [CrossRef]

38. Mas, J.F.; Flores, J.J. The application of artificial neural networks to the analysis of remotely sensed data. Int. J. Remote Sens. 2008, 29, 617-663. [CrossRef]

39. Bacour, C.; Baret, F.; Béal, D.; Weiss, M.; Pavageau, K. Neural network estimation of LAI, fAPAR, fCover and LAI $\times$ Cab, from top of canopy MERIS reflectance data: Principles and validation. Remote Sens. Environ. 2006, 105, 313-325. [CrossRef]

40. Liu, Z.Y.; Wu, H.F.; Huang, J.F. Application of neural networks to discriminate fungal infection levels in rice panicles using hyperspectral reflectance and principal components analysis. Comput. Electron. Agric. 2010, 72, 99-106. [CrossRef]

41. Christensen, L.K.; Bennedsen, B.S.; Jørgensen, R.N.; Nielsen, H. Modelling nitrogen and phosphorus content at early growth stages in spring barley using hyperspectral line scanning. Biosyst. Eng. 2004, 88, 19-24. [CrossRef]

42. Yi, Q.X.; Huang, J.F.; Wang, F.M.; Wang, X.Z.; Liu, Z.Y. Monitoring Rice Nitrogen Status Using Hyperspectral Reflectance and Artificial Neural Network. Environ. Sci. Technol. 2007, 41, 6770-6775. [CrossRef] [PubMed]

43. Wang, Y.; Wang, F.; Huang, J.; Wang, X.; Liu, Z. Validation of artificial neural network techniques in the estimation of nitrogen concentration in rape using canopy hyperspectral reflectance data. Int. J. Remote Sens. 2009, 30, 4493-4505. [CrossRef]

44. Sun, J.; Yang, J.; Shi, S.; Chen, B.; Du, L.; Gong, W.; Song, S. Estimating Rice Leaf Nitrogen Concentration: Influence of Regression Algorithms Based on Passive and Active Leaf Reflectance. Remote Sens. 2017, 9, 951. [CrossRef]

45. Panda, S.S.; Ames, D.P.; Panigrahi, S. Application of Vegetation Indices for Agricultural Crop Yield Prediction Using Neural Network Techniques. Remote Sens. 2010, 2, 673-696. [CrossRef] 